\title{
Palmitate-Induced Apoptosis of Microvascular Endothelial Cells and Pericytes
}

\author{
Sho-ichi Yamagishi, ${ }^{1}$ Tamami Okamoto, ${ }^{1}$ Shinjiro Amano, ${ }^{1}$ Yosuke Inagaki, ${ }^{1}$ Kohachiro Koga, ${ }^{1}$ \\ Mari Koga, ${ }^{1}$ Hiroshi Choei, ${ }^{2}$ Nobuyuki Sasaki, ${ }^{2}$ Seiji Kikuchi, ${ }^{3}$ Masayoshi Takeuchi, ${ }^{4}$ and Zenji \\ Makita $^{1}$ \\ ${ }^{1}$ Division of Endocrinology and Metabolism, Department of Medicine, Kurume University School \\ of Medicine, Kurume, Japan \\ ${ }^{2}$ Department of Neuropsychiatry, School of Medicine, Sapporo Medical University, Sapporo, Japan \\ ${ }^{3}$ Department of Neurology, Hokkaido University Graduate School of Medicine, Sapporo, Japan \\ ${ }^{4}$ Department of Biochemistry, Faculty of Pharmaceutical Science, Hokuriku University, Kanazawa, Japan \\ Accepted March 14, 2002
}

\begin{abstract}
Background: Recent observations in the EURODIAB Complications Study demonstrated that markers of insulin resistance are strong risk factors for retinopathy incidence in patients with diabetes. However, the molecular mechanism underlying this remains to be elucidated. In this study, we investigated the influence of palmitate, a major saturated free fatty acid in plasma, on the apoptotic cell death of cultured microvascular endothelial cells (EC) and retinal pericytes.

Materials and Methods: The intracellular formation of reactive oxygen species (ROS) was detected using the fluorescent probe CM- $\mathrm{H}_{2}$ DCFDA. DNA synthesis was determined by measuring $\left[{ }^{3} \mathrm{H}\right]$-thymidine incorporation into cells. DNA fragmentations of EC were quantitatively analyzed in an enzyme-linked immunosorbent
\end{abstract}

assay, and DNA laddering was evaluated on agarose gel electrophoresis.

Results: Palmitate increased ROS generation in microvascular EC. Furthermore, palmitate significantly inhibited DNA synthesis and induced apoptotic cell death in EC, which were completely prevented by an antioxidant, $\mathrm{N}$ acetylcysteine. Palmitate up-regulated pericyte mRNA levels of a receptor for advanced glycation end products (AGE), and thereby potentiated the apoptotic effects of AGE on pericytes.

Conclusions: The results suggest that palmitate could induce apoptotic cell death in microvascular EC and pericytes through the overgeneration of intracellular ROS, and thus be involved in the development of diabetic retinopathy.

\section{Introduction}

The vessels of the microvasculature are composed of two types of cells, endothelial cells (EC) and pericytes. We have shown that retinal pericytes not only regulate the growth, but also preserve the prostacyclin-producing ability and protect against lipid-peroxide-induced injury of co-cultured EC, thus providing a basis for understanding how diabetic retinopathy develops consequent to pericyte loss, the earliest histopathologic hallmark of diabetic retinopathy (1-3). Accelerated apoptosis of retinal vascular cells, as demonstrated by the development of acellular capillaries, was recently found to precede the characteristic vascular changes in human diabetic retinopathy (4).

Several major studies have established the value of strict control of blood glucose in preventing the microvascular complications of diabetes $(5,6)$. Other

Correspondence and reprint requests should be addressed to: Dr. Sho-ichi Yamagishi, Division of Endocrinology and Metabolism, Department of Medicine, Kurume University School of Medicine, Kurume 830-0011, Japan. Phone:181-942-31-7563; fax:181-942-35-8943; e-mail: shoichi@med.kurume-u.ac.jp. studies underline the importance of active metabolic intervention, including control of blood pressure and lipid as well as glucose, for the prevention of diabetic microvascular complications $(7,8)$. An increase in plasma free fatty acids is frequently observed in diabetes mellitus and the insulin-resistant state $(9,10)$. However, the influence of fatty acids on the apoptotic cell death of microvascular EC and pericytes remains to be elucidated.

In the present study, we investigated the effects of palmitate, which is a major saturated free fatty acid in plasma (11), on the apoptosis of cultured microvascular EC and retinal pericytes. Because we recently showed that advanced glycation end products (AGE) induced pericyte apoptosis through interaction with a receptor for AGE (RAGE) $(12,13)$, we further investigated whether palmitate could potentiate the cytopathic effects of AGE on pericytes.

\section{Materials and Methods}

BSA (fraction V), palmitate, $N$-acetylcysteine (NAC), and L-cycloserine were purchased from Sigma (St. Louis, MO, USA). D-glyceraldehyde, glycolaldehyde, 
and protease inhibitor cocktails were obtained from Nakalai Tesque (Kyoto, Japan). D-glucose was purchased from Wako Pure Chemical Industries, Ltd. (Osaka, Japan). $\left[{ }^{3} \mathrm{H}\right]$-Thymidine, $\left[\gamma^{32} \mathrm{P}\right]$ ATP, and Hybond- $\mathrm{N}^{+}$nylon membrane were obtained from Amersham Pharmacia Biotech (Buckinghamshire, United Kingdom). Reverse transcriptase and T4 polynucleotide kinase were purchased from Takara (Kyoto, Japan).

\section{Cells}

EC from human skin microvessels were maintained in E-BM medium supplemented with $5 \%$ fetal bovine serum (FBS), $0.4 \%$ bovine brain extracts, $10 \mathrm{ng} / \mathrm{ml}$ human epidermal growth factor, and $1 \mu \mathrm{g} / \mathrm{ml}$ hydrocortisone according to the manufacturer's instructions (Clonetics Corp., San Diego, CA, USA) (14). Cells at 5-10 passages were used for the experiments. Palmitate treatment was carried out in medium lacking epidermal growth factor and hydrocortisone. Pericytes were isolated from bovine retinas and maintained in Dulbecco's modified Eagle's medium (DMEM; Gibco BRL, Rockville, MD, USA) supplemented with $20 \%$ FBS (ICN Biomedicals Inc., Aurora, OH, USA) (15). Palmitate and AGE treatments were carried out in medium containing $2 \%$ FBS.

\section{Intracellular Reactive Oxygen Species}

The intracellular formation of reactive oxygen species (ROS) was detected using the fluorescent probe CM$\mathrm{H}_{2}$ DCFDA (Molecular Probes Inc., Eugene, OR, USA) as described previously (16). Briefly, cells $(1 \times$ $10^{5} / 96$ well-plate) were loaded with $10 \mu \mathrm{mol} / \mathrm{L}$ CM$\mathrm{H}_{2}$ DCFDA, incubated for $45 \mathrm{~min}$ at $37^{\circ} \mathrm{C}$, and analyzed in a EZS-FL fluorescent plate reader (Asahi Techno Glass, Tokyo, Japan) using the EZScan-FL for Windows program.

\section{Measurement of $\left.{ }^{3} \mathrm{H}\right]$-Thymidine Incorporation into EC and Pericytes}

EC were incubated with or without $100 \mu \mathrm{M}$ palmitate in the presence or absence of NAC for $24 \mathrm{hr}$, and then $\left[{ }^{3} \mathrm{H}\right]$-thymidine incorporation into the EC was determined as described previously (17). Pericytes were treated with $100 \mu \mathrm{g} / \mathrm{ml}$ of various types of AGE-BSA or nonglycated BSA in the presence or absence of palmitate for 2 days, and then $\left[{ }^{3} \mathrm{H}\right]-$ thymidine incorporation was measured (17).

\section{Measurement of Apoptotic Cell Death in EC and Pericytes}

EC were incubated with or without $100 \mu \mathrm{M}$ of palmitate in the presence or absence of NAC for $24 \mathrm{hr}$. The cells were then lysed and the supernatant was analyzed in an enzyme-linked immunosorbent assay (ELISA) for DNA fragments (Cell Death Detection ELISA, Roche Molecular Biochemicals, Mannheim, Germany). Pericytes were treated with $100 \mu \mathrm{g} / \mathrm{ml}$ of various types of AGE-BSA or nonglycated BSA in the presence or absence of $100 \mu \mathrm{M}$ of palmitate for 2 days, and then apoptotic cell death was measured.

\section{Primers and Probes}

Sequences of the upstream and downstream primers and the internal probe used in the quantitative RT-PCR for detecting bovine RAGE and $\beta$-actin mRNAs were the same as described previously (12).

\section{Poly $(A)^{+}$RNA Isolation and Quantitative RT-PCR}

Poly(A) ${ }^{+}$RNAs were isolated (18) from pericytes treated with or without $100 \mu \mathrm{M}$ of palmitate for 2 days, and then analyzed by RT-PCR as described previously (19). Ten-microliter aliquots of each RT-PCR reaction mixture were electrophoresed on a $1.2 \%$ agarose gel, transferred to a Hybond $-\mathrm{N}^{+}$ nylon membrane, and the membrane was then hybridized with the respective ${ }^{32} \mathrm{P}$-end labeled probes (20). The amounts of the poly $(A)^{+}$RNA templates (30 ng) and the cycle numbers ( 35 cycles) for amplification were chosen in quantitative ranges where the reactions proceeded linearly, which had been determined by plotting signal intensities as functions of the template amounts and cycle numbers $(12,21)$. Signal intensities of hybridized bands were measured by microcomputer-assisted NIH Image (Version 1.56).

\section{Preparation of AGE Proteins}

AGE proteins were prepared as described previously (22). Briefly, BSA was incubated under sterile conditions with D-glucose for 8 weeks or with D-glyceraldehyde or glycolaldehyde for 7 days. Then unincorporated sugars were removed by dialysis against PBS. Control nonglycated BSA was incubated in the same conditions except for the absence of reducing sugars. Preparations were tested for endotoxin using Endospecy ES-20S system (Seikagaku Co., Tokyo, Japan); no endotoxin was detectable.

\section{Statistical Analysis}

All values are presented as means \pm SEM. Statistical significance was evaluated using the Student's $t$-test for paired comparison; $p<0.05$ was considered significant.

\section{Results}

Effects of Palmitate on ROS Generation in EC

As shown in Figure 1, palmitate significantly increased intracellular ROS generation in human microvascular EC. ROS generation in EC was increased by approximately 1.4-fold after treatment with $100 \mu \mathrm{M}$ palmitate for $4 \mathrm{hr}$.

\section{Effects of Palmitate on $\left.{ }^{3} \mathrm{H}\right]$-Thymidine}

Incorporation into $\mathrm{EC}$

We investigated the effects of palmitate on $\left[{ }^{3} \mathrm{H}\right]$ thymidine incorporation into EC. As shown in 


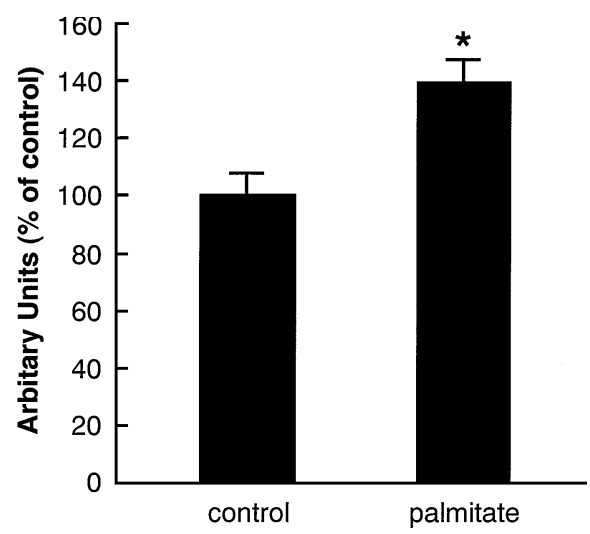

Fig. 1. Effects of palmitate on intracellular ROS generation in microvascular EC. Cells were treated with $100 \mu \mathrm{M}$ palmitate for $24 \mathrm{hr}$, and then ROS were quantitatively analyzed. ${ }^{*} p<0.01$ compared to the value of the control without palmitate.

Figure 2, palmitate significantly inhibited DNA synthesis in EC. EC displayed a $50 \%$ decrease in thymidine incorporation when exposed to $100 \mu \mathrm{M}$ palmitate for $24 \mathrm{hr}$. To investigate whether intracellular ROS generation was involved in the inhibition of DNA synthesis induced by palmitate, the effects of NAC, an intracellular radical scavenger, on $\left[{ }^{3} \mathrm{H}\right]-$ thymidine incorporation into EC were examined. NAC was found to completely prevent the effects of palmitate (Fig. 2). L-cycloserine, an inhibitor of serine palmitoyltransferase, which ultimately blocks de novo ceramide synthesis, did not affect the palmitate-induced inhibition of DNA synthesis in EC (data not shown).

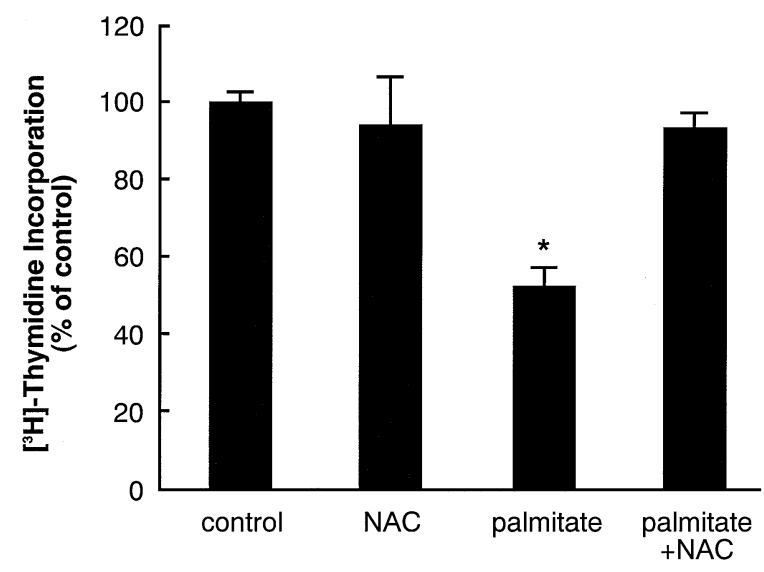

Fig. 2. Effects of palmitate on $\left[{ }^{3} \mathrm{H}\right]$-thymidine incorporation into microvascular EC. Cells were treated with or without $100 \mu \mathrm{M}$ of palmitate in the presence or absence of NAC for $24 \mathrm{hr}$. For the last $4 \mathrm{hr}$ of culture, the cells were pulsed with $2 \mu \mathrm{Ci}$ of $\left[{ }^{3} \mathrm{H}\right]$-thymidine. After cells were washed with ice-cold PBS, $\left[{ }^{3} \mathrm{H}\right]$-thymidine incorporation into the cells was assayed. The percentage of $\left[{ }^{3} \mathrm{H}\right]$-thymidine incorporation is indicated on the ordinate and related to the value without palmitate or NAC. ${ }^{*} p<0.01$ compared to the value of the control without palmitate or NAC.

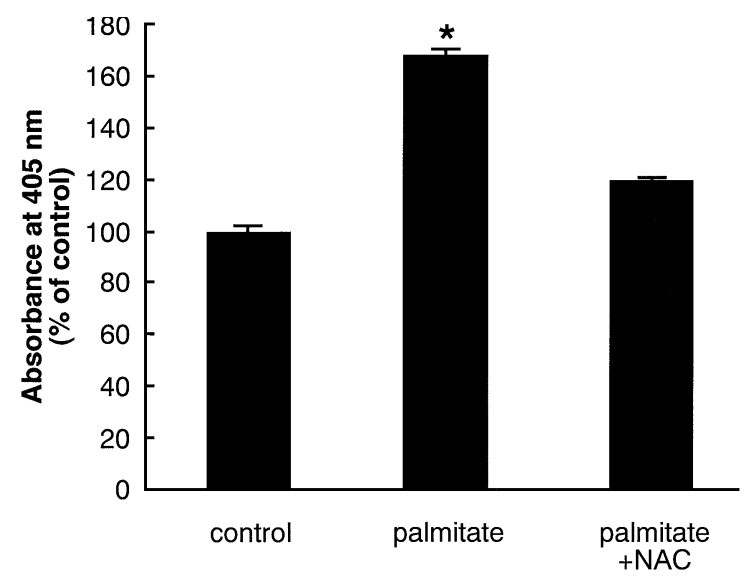

Fig. 3. Effects of palmitate on apoptotic cell death in microvascular EC. EC were treated with or without $100 \mu \mathrm{M}$ palmitate in the presence or absence of NAC for $24 \mathrm{hr}$. Then cells were lysed and the supernatant analyzed by ELISA for DNA fragments. The percentage of absorbance at $405 \mathrm{~nm}$ is indicated on the ordinate and related to the value of the control without palmitate or NAC. ${ }^{*} p<0.01$ compared to the value of the control of without palmitate or NAC.

\section{Effects of Palmitate on Apoptotic Cell Death in EC}

We next investigated whether palmitate could induce apoptotic cell death in microvascular EC. Apoptosis is characterized by DNA fragmentation due to endogenous endonuclease activation (23). Therefore, DNA fragments in the cytoplasm of EC exposed to palmitate were measured quantitatively. As shown in Figure 3, palmitate significantly induced apoptotic cell death in EC. As in the case of DNA synthesis, the effect of palmitate on apoptotic cell death in EC was significantly prevented by NAC treatment. Furthermore, it was also found that palmitate actually induced DNA ladder formation in EC (data not shown).

\section{Effects of Palmitate on RAGE Gene Expression in Retinal Pericytes}

We recently found that AGE induced apoptotic cell death in bovine retinal pericytes through interaction with RAGE (13). Therefore, poly(A) ${ }^{+}$RNAs were isolated from pericytes treated with $100 \mu \mathrm{M}$ of palmitate for 2 days, and analyzed by a quantitative RT-PCR technique to determine the effect of palmitate on the expression of RAGE genes. As shown in Figure 4, palmitate up-regulated RAGE mRNA levels in pericytes by approximately 2 -fold compared with the basal level. An increase in the expression level of RAGE proteins was also confirmed in palmitate-treated pericytes (data not shown).

\section{Effects of Palmitate on $\left.{ }^{3} \mathrm{H}\right]$-Thymidine Incorporation into Pericytes}

To find any functional role of the palmitate-induced RAGE overexpression, pericytes were incubated 

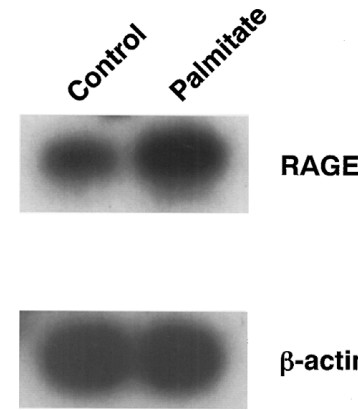

$\beta$-actin

Fig. 4. Effects of palmitate on RAGE gene expression in retinal pericytes. Cells were treated with or without $100 \mu \mathrm{M}$ of palmitate for 2 days, and then $30 \mathrm{ng}$ poly(A) ${ }^{+}$RNAs were transcribed and amplified by PCR. Each lower panel shows the expression of $\beta$-actin genes. PCR amplification for $\beta$-actin mRNA was performed for 20 cycles.

with $100 \mu \mathrm{g} / \mathrm{ml}$ of various types of AGE-BSA or nonglycated BSA in the presence or absence of palmitate. Although palmitate did not affect DNA synthesis in the pericytes exposed to nonglycated BSA, palmitate-treated pericytes were more sensitive to AGE because the growth inhibitory effects of AGE on pericytes were significantly enhanced in these pericytes (Fig. 5).

\section{Effects of Palmitate on Apoptotic Cell Death in Pericytes}

We next investigated whether palmitate-induced RAGE overexpression is actually related to pericyte apoptosis. As shown in Figure 6, although palmitate

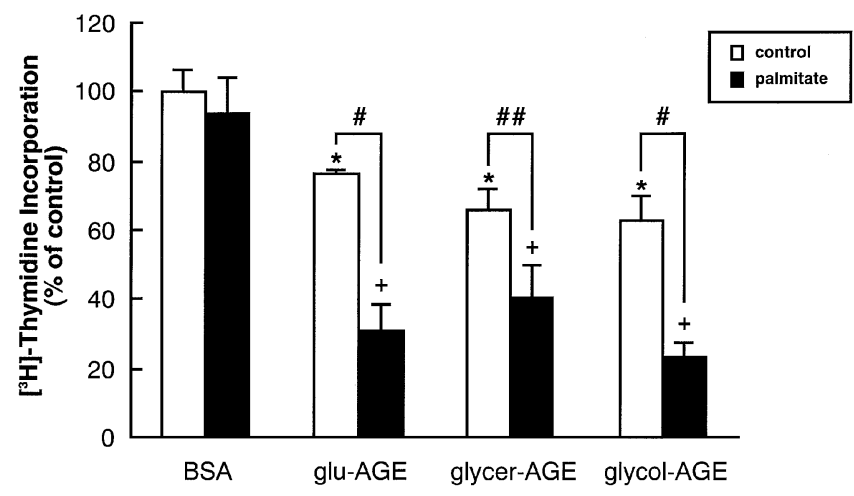

Fig. 5. Effects of palmitate on $\left[{ }^{3} \mathrm{H}\right]$-thymidine incorporation into retinal pericytes. Cells were treated with $100 \mu \mathrm{g} / \mathrm{ml}$ of various types of AGE-BSA or nonglycated BSA in the presence or absence of $100 \mu \mathrm{M}$ of palmitate for 2 days. For the last $4 \mathrm{hr}$ of culture, the cells were pulsed with $2 \mu \mathrm{Ci}$ of $\left[{ }^{3} \mathrm{H}\right]-$ thymidine. After cells were washed with ice-cold PBS, $\left[{ }^{3} \mathrm{H}\right]-$ thymidine incorporation into the cells was assayed. The percentage of $\left[{ }^{3} \mathrm{H}\right]$-thymidine incorporation is indicated on the ordinate and related to the value with nonglycated BSA alone. Glu-AGE, glucose-derived AGE; glycer-AGE, glyceraldehydederived AGE; glycol-AGE, glycolaldehyde-derived AGE. ${ }^{*} p<0.01$ compared to the value of the control with nonglycated BSA alone. ${ }^{+} p<0.01$ compared to the value of the control with nonglycated BSA and palmitate. ${ }^{\# \#} p<0.05$. ${ }^{\#} p<0.01$ compared to the value of non-palmitate-treated cells.

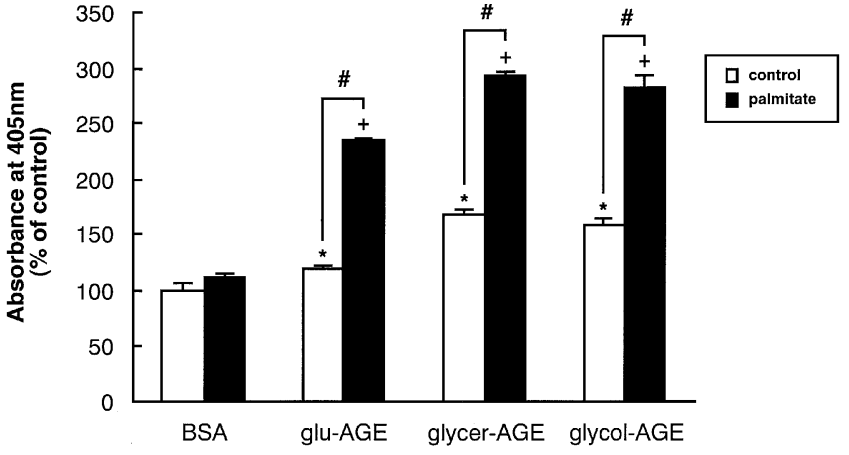

Fig. 6. Effects of palmitate on apoptotic cell death in pericytes. Pericytes were treated with $100 \mu \mathrm{g} / \mathrm{ml}$ of various types of AGE-BSA or nonglycated BSA in the presence or absence of $100 \mu \mathrm{M}$ of palmitate for 2 days. Then cells were lysed and the supernatant analyzed by ELISA for DNA fragments. The percentage of absorbance at $405 \mathrm{~nm}$ is indicated on the ordinate and related to the value of the control with nonglycated BSA alone. Glu-AGE, glucose-derived AGE; glycer-AGE, glyceraldehyde-derived AGE; glycol-AGE, glycolaldehydederived AGE. * $p<0.01$ compared to the value of the control with nonglycated BSA alone. ${ }^{+} p<0.01$ compared to the value of the control with nonglycated BSA and palmitate. ${ }^{\#} p<0.01$ compared to the value of non-palmitate-treated cells.

itself did not affect apoptotic cell death in pericytes exposed to nonglycated BSA, AGE-induced pericyte apoptosis was significantly potentiated by treatment with $100 \mu \mathrm{M}$ of palmitate.

\section{Discussion}

The present study demonstrates for the first time that palmitate, a major saturated free fatty acid in plasma, induces growth retardation and apoptotic cell death in microvascular EC. The evidence that it was palmitate-induced intracellular ROS generation, independent of ceramide synthesis, that caused the cytopathic effects of palmitate is as follows. First, palmitate increased intracellular ROS generation in microvascular EC (Fig. 1). Second, NAC, an intracellular radical scavenger, completely prevented the palmitate-induced DNA synthesis inhibition as well as apoptosis in EC (Figs. 2 and 3). Third, biochemical inhibition of de novo ceramide synthesis did not affect the growth inhibitory effect of palmitate on EC (data not shown). These observations are consistent with recent studies by Listenberger et al. (24), which showed that palmitate induced apoptosis of Chinese hamster ovary cells through the generation of ROS.

We previously showed that leptin induces ROS generation and monocyte chemoattractant protein-1 expression in aortic EC by increasing fatty acid oxidation (14). Because an increase of plasma free fatty acids, including palmitate, is frequently observed in diabetes and the insulin-resistant state $(9,10)$, ROS overgeneration through mitochondrial fatty acid oxidation in EC might contribute to the development of diabetic micro- and macrovascular complications. 
Recent observations in the EURODIAB Complications Study demonstrated that markers of insulin resistance are strong risk factors for retinopathy incidence in patients with diabetes, and this supports our hypothesis (25).

We recently found that AGE, glycated protein derivatives formed at an accelerated rate in diabetes, could induce the apoptotic cell death of retinal pericytes through interaction with RAGE. In the present study, palmitate supplementation was found to potentiate the cytopathic effects of AGE on pericytes through overexpression of RAGE proteins. Because we previously showed that RAGE gene expression is regulated by redox-sensitive transcriptional factor nuclear factor- $\kappa \mathrm{B}$ (NF- $\kappa \mathrm{B})$, palmitate-induced ROS generation and the resultant activation of NF- $\kappa \mathrm{B}$ may be involved in RAGE protein overexpression in pericytes (26).

Accelerated apoptosis of retinal microvascular wall cells such as EC and pericytes was recently found to precede the characteristic diabetic vascular changes and may therefore be a key event in the early phase of development of diabetic retinopathy (4). Bax protein is increased in the retina of diabetic subjects and is associated with pericyte apoptosis (4). Therefore, palmitate-induced potentiation of the AGE-RAGE interaction and the subsequent ROS generation could be implicated in Bax protein induction in diabetic retinopathy (27).

In conclusion, the present study indicates that palmitate, a major saturated free fatty acid in plasma, induces programmed cell death of microvascular EC through the overgeneration of intracellular ROS. Palmitate also potentiates the apoptotic effects of AGE on retinal pericytes. The results suggest that palmitate may play some role in the development of diabetic retinopathy.

\section{Acknowledgments}

This work was supported in part by Grants of Venture Research and Development Centers from the Ministry of Education, Culture, Sports, Science and Technology, Japan; the Suzuken Memorial Foundation, Japan; the Hukuriku University Foundation, Japan; and the Mochida Memorial Foundation for Medical and Pharmaceutical Research, Japan.

\section{References}

1. Cogan DG, Toussaint D, Kuwabara T. (1961) Retinal vascular patterns. IV. Diabetic retinopathy. Arch. Ophthalmol. 66: 366-378.

2. Yamagishi S, Kobayashi K, Yamamoto H. (1993) Vascular pericytes not only regulate growth, but also preserve prostacyclin-producing ability and protect against lipid peroxide-induced injury of co-cultured endothelial cells. Biochem. Biophys. Res. Commun. 190: 418-425.

3. Yamagishi S, Hsu CC, Kobayashi K, Yamamoto H. (1993) Endothelin 1 mediates endothelial cell-dependent proliferation of vascular pericytes. Biochem. Biophys. Res. Commun. 191: 840-846.
4. Podestá F, Romeo G, Liu WH, et al. (2000) Bax is increased in the retina of diabetic subjects and is associated with pericyte apoptosis in vivo and in vitro. Am. J. Pathol. 156: 10251032.

5. Diabetes Control and Complications Trial Research Group. (1993) The effects of intensive treatment of diabetes on the development and progression of long-term complications in insulin-dependent diabetes mellitus. N. Engl. J. Med. 329: 977-986.

6. United Kingdom Prospective Diabetes Study Group (UKPDS). (1998) Intensive blood-glucose control with sulfonylureas or insulin compared with conventional treatment and risk of complications in patients with type 2 diabetes (UKPDS33). Lancet 352: 837-853.

7. Heart Outcomes Prevention Evaluation (HOPE) Study. (2000) Effects of ramipril on cardiovascular and microvascular outcomes in people with diabetes mellitus: results of the HOPE study and MICRO-HOPE substudy. Lancet 355: 253-259.

8. Orchard TJ, Kuller LH, Forrest KYZ, Becker DJ. (2001) Lipid and blood pressure treatment goals for type 1 diabetes. Diabetes Care 24: 1053-1059.

9. Shimabukuro M, Zhou YT, Levi M, Unger RH. (1998) Fatty acid-induced $\beta$ cell apoptosis: a link between obesity and diabetes. Proc. Natl. Acad. Sci. U.S.A. 95: 2498-2502.

10. Bjorntorp P. (1994) Fatty acids, hyperinsulinemia and insulin resistance: which comes first? Curr. Opin. Lipidol. 5: 166-174.

11. Inoguchi T, Li P, Umeda F, et al. (2000) High glucose level and free fatty acid stimulate reactive oxygen species production through protein kinase $\mathrm{C}$-dependent activation of $\mathrm{NAD}(\mathrm{P}) \mathrm{H}$ oxidase in cultured vascular cells. Diabetes 49: 1939-1945.

12. Yamagishi S, Hsu CC, Taniguchi M, et al. (1995) Receptormediated toxicity to pericytes of advanced glycosylation end products: a possible mechanism of pericyte loss in diabetic microangiopathy. Biochem. Biophys. Res. Commun. 213: 681-687.

13. Yamagishi S, Amano S, Inagaki Y, et al. (2002) Advanced glycation end products-induced apoptosis and overexpression of vascular endothelial growth factor in bovine retinal pericytes. Biochem. Biophys. Res. Commun. 290: 973-978.

14. Yamagishi S, Fujimori H, Yonekura H, Yamamoto Y, Yamamoto H. (1998) Advanced glycation endproducts inhibit prostacyclin production and induce plasminogen activator inhibitor-1 in human microvascular endothelial cells. Diabetologia 41: 1435-1441.

15. Yamagishi S, Yonekura H, Yamamoto Y, et al. (1999) Vascular endothelial growth factor acts as a pericyte mitogen under hypoxic conditions. Lab. Invest. 79: 501-509.

16. Yamagishi S, Edelstein D, Du XL, Kaneda Y, Guzman M, Brownlee M. (2001) Leptin induces mitochondrial superoxide production and monocyte chemoattractant protein-1 expression in aortic endothelial cells by increasing fatty acid oxidation via protein kinase A. J. Biol. Chem. 276: 2509625100.

17. Yamagishi S, Yamamoto Y, Harada S, Hsu CC, Yamamoto H. (1996) Advanced glycosylation end products stimulate the growth but inhibit the prostacyclin-producing ability of endothelial cells through interactions with their receptors. FEBS Lett. 384: 103-106.

18. Yamagishi S, Yonekura H, Yamamoto Y, et al. (1997) Advanced glycation end products-driven angiogenesis in vitro. Induction of the growth and tube formation of human microvascular endothelial cells through autocrine vascular endothelial growth factor. J. Biol. Chem. 272: 8723-8730.

19. Yamagishi S, Kawakami T, Fujimori H, et al. (1999) Insulin stimulates the growth and tube formation of human microvascular endothelial cells through autocrine vascular endothelial growth factor. Microvasc. Res. 57: 329-339.

20. Yamagishi S, Fujimori H, Yonekura H, Tanaka N, Yamamoto H. (1999) Advanced glycation endproducts accelerate calcification in microvascular pericytes. Biochem. Biophys. Res. Commun. 258: 353-357. 
21. Nomura M, Yamagishi S, Harada S, et al. (1995) Possible participation of autocrine and paracrine vascular endothelial growth factors in hypoxia-induced proliferation of endothelial cells and pericytes. J. Biol. Chem. 270: 28316-28324.

22. Takeuchi M, Bucala R, Suzuki T, et al. (2000) Neurotoxicity of advanced glycation end-products for cultured cortical neurons. J. Neuropathol. Exp. Neurol. 59: 1094-1105.

23. Schwartzman RA, Cidlowski JA. (1993) Apoptosis: the biochemistry and molecular biology of programmed cell death. Endocrine Rev. 14: 133-151.

24. Listenberger LL, Ory DS, Schaffer JE. (2001) Palmitateinduced apoptosis can occur through a ceramide-independent pathway. J. Biol. Chem. 276: 14890-14895.
25. Chaturvedi N, Songini M, Sjoelie AK, et al. (2001) Markers of insulin resistance are strong risk factors for retinopathy incidence in type 1 diabetes. Diabetes Care 24: 284-289.

26. Tanaka N, Yonekura H, Yamagishi S, Fujimori H, Yamamoto Y, Yamamoto H. (2000) The receptor for advanced glycation end products is induced by the glycation products themselves and tumor necrosis factor- $\alpha$ through nuclear factor $-\kappa \mathrm{B}$, and by estradiol through $\mathrm{Sp}-1$ in human vascular endothelial cells. J. Biol. Chem. 275: 25781-25790.

27. Yan SD, Schmidt AM, Anderson GM, et al. (1994) Enhanced cellular oxidant stress by the interaction of advanced glycation end products with their receptors/binding proteins. J. Biol. Chem. 269: 9889-9897. 